\title{
Development and analysis of an opportunity cost simulation accounting for the spatial distributions of local forest management
}

\author{
T. Nakajima, H. Kanomata, N. Shiraishi, M. Matsumoto
}

Nakajima T., Kanomata H., Shiraishi N., Matsumoto M., 2017. Development and analysis of an opportunity cost simulation accounting for the spatial distributions of local forest management. Ann. For. Res. 60(1): 145-159.

\begin{abstract}
We describe the development of a simulation based on neighbor relationships between small stands forming many sub compartments in a forested area. We used a Geographic Information System (GIS) to simulate local forest management plans. The distribution and intensity of different silvicultural practices were visualized. We also determined whether, at specified rates, the implementation of forestry operations was optimum for the desired outcomes in specific compartments. Based on the results, we discuss the tradeoff between two silvicultural strategies. First, the rational economic strategy, which generally focuses on implementing silvicultural prescriptions in some compartments. Second, the environmental strategy, which generally focuses on implementing silvicultural prescriptions in all compartments, taking account of environmental forestry practices. The difference between profits under the two strategies at the study site was approximately $20 \%$, and this economic difference could be considered to represent "opportunity costs" of a commitment to environmentally conscious management. We created the simulation to map the strategies based on the location of existing forest roads and any special constraints. In addition, the model could be used as a decision-making tool for considering the tradeoff between environmental and economic strategies. Keywords forestry profits, geographic information system, opportunity costs, silvicultural allocation, small stands
\end{abstract}

Authors. Tohru Nakajima (nakajima@fr.a.u-tokyo.ac.jp), Norihiko Shiraishi - The University of Tokyo, Laboratory of Forest Management, Graduate School of Agricultural and Life Sciences, the University of Tokyo, 1-1-1 Yayoi, Bunkyo-ku, Tokyo 113-8657, Japan; Hidesato Kanomata - Forestry and Forest Products Research Institute, 1 Matsunosato, Tsukuba 305-8687, Japan; Mitsuo Matsumoto - Hokkaido Research Center, Forestry and Forest Products Research Institute, 7 Hitsujigaoka, Toyohira, Sapporo, Hokkaido 062-8516, Japan.

Manuscript received April 1 ${ }^{\text {st }}$ 2016; revised March 1 ${ }^{\text {st }}, 2017$; accepted March 7, 2017; online first April 12, 2017. 


\section{Introduction}

Maximizing profit has a significant influence on forestry rationale and timber productivity (Clutter et al. 1983). However, forest management plans should also consider environmental aspects, such as landscape, aesthetics, biodiversity and carbon sequestration (Pukkala 2002). In the context of global carbon emissions, it is important for Japanese forestry policy to extend the political incentive for appropriate forest management via an activity-based approach (UNFCCC 2012). In Japan, about $60 \%$ of plantation forests are privately owned. The many small scale planted forest stands managed by numerous independent private forest owners make it difficult to have a coherent management strategy. Statistics reveal that the forest area owned by more than $70 \%$ of non-industrial private forest owners (NIPFs) is generally less than 5 ha (Forestry Agency 2007). This fact means that the plantation forests are finely divided, with numerous private owners. If each small-scale stand is managed independently, it is difficult to establish broad-scale management plans and long term strategies. Therefore, it would be useful for forestry actors, such as forestry cooperatives, to develop a model to predict local-scale activities in the numerous planted stands. Additionally, under current Japanese economic conditions, the financial merits of forestry activity are relatively low as a result of falling timber prices since the import liberalization of timber in 1964. According to previous work (Hiroshima \& Nakajima 2006), the extent of the forestry area in which no forestry management has been implemented for a long time (10 years or more) is increasing in the Japanese plantation forest. Therefore, rational forest management strategies are required, along with a decision-making system to assist in predicting forestry profitability according to planned actions.

The Ministry of Agriculture, Forestry and Fisheries (Japan) is trying to increase self-suf- ficiency in timber. For Japanese national government policy, it is also important to establish a management system to plan timber production. Previous studies have generally shown that small-scale stands could be used to maintain the environmental value of Japan's forests. Although some studies have addressed the merits of broader-scale forest management plans (Nakajima et al. 2009a, Kittredge 2005), little work has focused on the analysis and visualization of the relationships between small stands in local forest areas. The current study, therefore, was intended to develop such a visualization system by combining an existing forest profitability model with a Geographic Information System (GIS), and quantifying the opportunity costs as a trade-off between environmental and economic strategies in forestry. Because forest owners are increasingly less motivated to undertake forestry operations (Nakajima et al. 2009b), silvicultural activities, including commercial cutting, are not being implemented on a large scale. This fact means that Japanese carbon sequestration is likely to be underestimated because the carbon stock of the forest sector is calculated on the basis that active management is occurring (UNFCCC 2002). Regarding environmental functions - aesthetics, biodiversity and carbon sequestration - the spatial distribution of various activities is strongly related to the tradeoff between economic rationalistic ideas and environmental value. These tradeoffs can be quantified as "opportunity costs", which are helpful for forest managers and policy makers when considering the financial support required to balance environmental values against economic rationalistic aims (Pukkala 2002).

Many previous studies of forest management have estimated the opportunity costs. Generally, they showed the trade-off between certain benefits (economic, for example) and environmental functions, or forestry against another industry. Fox et al. (1989) estimated the opportunity costs between agriculture and forestry. Lowell et al. (2008) analyzed the tradeoff between wood production and protec- 
tion from wildfire. Anitha et al. (2008) evaluated the market sustainability and production for traditional bamboo, and included an analysis of the opportunity costs. Layton and Siikamaki (2009) developed models for estimating opportunity costs of conservation in transitional landscapes. However, few studies show the opportunity costs by considering the spatial and rational patterns of forestry harvesting as an economic activity. This study, therefore, aimed to develop a simulation of harvesting distribution to be optimized for maximizing forestry profits based on existing models, and to estimate the trade-off between economic harvesting and environmental harvesting based on spatial simulations using a GIS.

\section{Materials and methods}

\section{Study site}

We selected Morotsuka village, located in Miyazaki Prefecture, Japan (Fig. 1) as the study site for this research. The timber productivity of this site is amongst the highest in Japan (Miyazaki Prefecture Government 2015). The climate is warm temperate, with a mean annual temperature of $14{ }^{\circ} \mathrm{C}$, and mean annual rainfall of $2445 \mathrm{~mm}$. Of the 17785 ha of forest, about

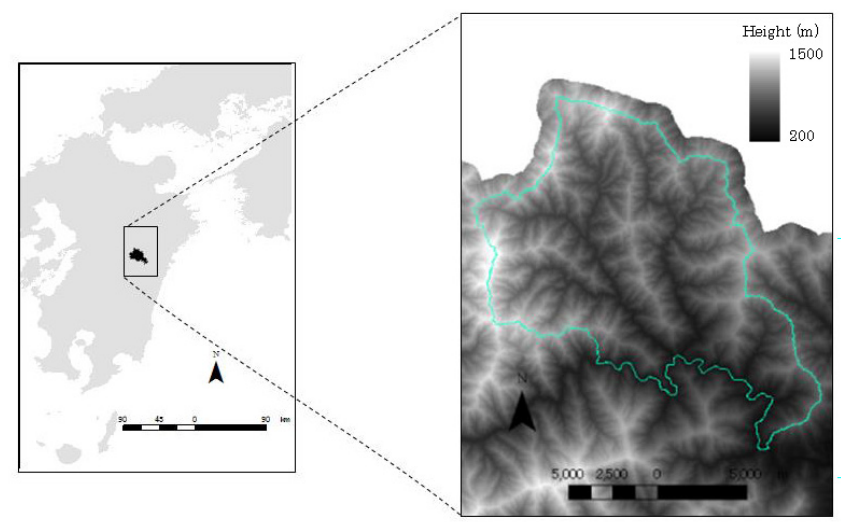

Figure 1 Location of Morotsuka village, showing the elevation of the study site. The blue line indicates the forest boundary line for the village
$71 \%$ (12541 ha) is plantation. We selected areas that had a bell-shaped tree age distribution, which is standard in Japanese planted forests of Cryptomeria japonica (Forestry Agency 2007). As shown in figure 2, Cryptomeria japonica in the target area is mostly between 30 and 50 years old. In 2004, this study site was certificated by the Forest Stewardship Council (FSC). Therefore, it must be not only economically sustainable, but also deliver environmental forestry functions defined by the independent organization (Gulbrandsen 2005).

\section{Data analysis}

\section{Modelling joint implementation of harvesting}

We introduced the models to a previous optimization (Nakajima et al. 2016) for joint implementation of harvesting in order to visualize spatial intensity of forest management as follows.

For this model, the first input is the table showing adjacency relationships between the sub-compartments. In this study, we refer to this table as the "adjacency table". This adjacency table shows the connections between sub-compartments. Before any analysis, all connections were determined for each sub-compartment. Next, the data set including silvicultural prescriptions (Helms 1998) was input; these are any deliberate courses of action to manipulate forestry vegetation to achieve specific management objectives for each sub-compartment. These prescriptions include short ( $<76$ years) and long ( $>75$ years) rotation prescriptions. Based on the prediction models of harvesting profitability, depending on the rotation prescription, the following categories of stand plans were defined: plans based on optimum short rotations of periods up to 75 years; and plans based 


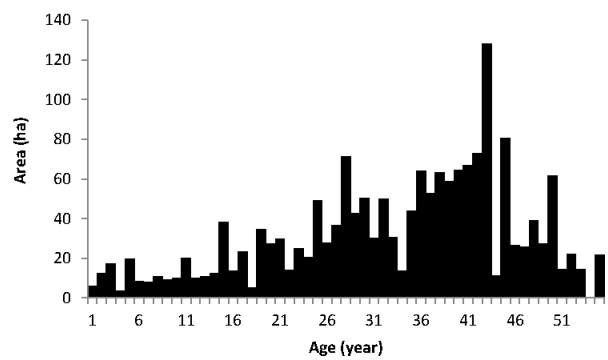

Figure 2 The area of the target planted stand, by age, in Morotsuka village

on optimum rotations for long periods, from 76 years. We optimized the combinations of prescriptions for each stand by selecting suitable options from these prescription categories or "abandonment", in which no forestry activities are implemented. The total profits derived from the selected plans for each stand were estimated by summarizing the profits calculated for each stand under a discount rate of $3 \%$, as used in previous studies (Nakajima et al. 2011a, Oka 2006). The lengths of the rotations were estimated by maximizing NPV (Davis \& Johanson 1987) according to these previous studies.

Based on the input data and information provided by local forestry workers, including the forestry cooperative, some rules were applied, as follows.

(1) Because the trees are harvested by forestry vehicles at the study site, only sub-compartments with forest roads can be harvested.

(2) A forest road can be established in a sub-compartment in which the trees were harvested by thinning or final cutting operations.

(3) Some sub-compartments do not include a forest road. These sub-compartments can be harvested at the same time as a neighboring sub-compartment that does have a forest road, and a road into them established at that time. Based on information from forestry workers, it was assumed that the forest road density for harvesting per sub-compartment would be $50 \mathrm{~m} / \mathrm{ha}$.

(4) After the establishment of a forest road, 148 the sub-compartment could be harvested independently.

(5) The cost of establishment and maintenance of forest roads was assumed to be 2000 yen/ha and $100 \mathrm{yen} / \mathrm{m} \cdot$ year, respectively.

Based on these rules, two rates of establishment of forest plans were assumed, taking into account the adjacency relationships: The "connector rate" and the "prescription rate" can have any value between 0 and 1 . If the connector rate is changed between 0 and 1 , the starting year for harvest can be changed for harvest synchronization. These two rates can have a value between these two extreme ratios from 0 to 1 as mentioned below. The general framework of the algorithm is shown in the figure 3. One connector rate and one prescription ratio are given for one connection and one sub-compartment, respectively. The connector rate was determined, assuming the following case. There are three sub-compartments: the first, second and third, respectively. The first sub-compartment has a forest road, the second and third sub-compartments do not. We explain about the harvests in two adjoining compartments being synchronized as follows. The first and second sub-compartments are connected by a single connection. The second and third sub-compartments are connected by a single connection. In this situation, we considered the case that the first and second sub-compartments were harvested simultaneously. The year when the second sub-compartment had a forest road constructed is called the "starting year for harvest". The starting year for harvest in the second sub-compartment would depend on the year of harvesting being synchronized with the year of harvest in the first sub-compartment. So, there is a range of options regarding the starting year for harvest. When the second sub-compartment is harvested in a given year $(y)$, it is necessary to clarify whether " $y$ " is the starting year for harvest or not. Determining whether " $y$ " is the starting year for harvest depends on the year in which the second sub-compartment is harvested, this 


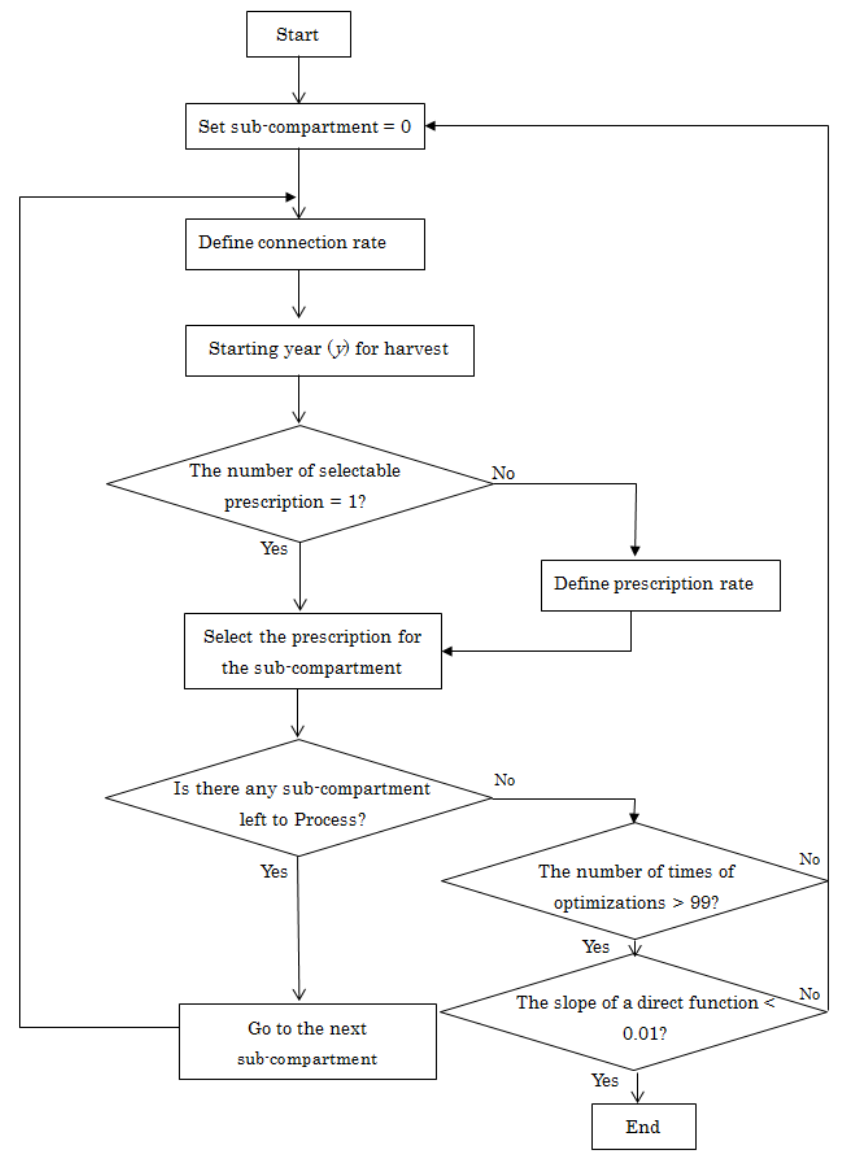

Figure 3 The general framework for decision of prescription in each sub-compartment

must be at the same time as first sub-compartment which has the forest road.

Within the possible range of starting years for harvest, a connector rate of 0 indicates the earliest starting year for harvest, whilst a connector rate of 1 indicates the latest starting year for harvest. If the connector rate is changed between 0 and 1 , the starting year for harvest can be changed by harvest synchronization.

A connector rate of " -1 " indicates that the harvests in two adjoining compartments being synchronized cannot be successfully defined. In the second and third sub-compartments, there is also a relationship between connection and the connector rate. As mentioned above, there are connector rates associated with the connections between all neighboring sub-compartments. Harvest synchronization is controlled in the model by changing these connector rates between 0 and 1 .

In some sub-compartments, a number of prescriptions could fulfill all the conditions controlled by connector rates. To elucidate, we consider the following example. We assume two prescriptions with a difference in their rotation periods. However, there is no difference in the commercial thinning age for the two prescriptions. In this situation, we assume the case that the starting year for harvest was chosen in order to synchronize commercial thinning based on the connector rate, as mentioned above. If there is no difference in the commercial thinning ages in future years between the two prescriptions, they could fulfill all the conditions controlled by connector rates. In this case, it is necessary to select one prescription for each sub-compartment. Where there is a choice, the prescription is selected based on the "prescription rate". All the prescriptions that could fulfill all the conditions controlled by connector rates, were arranged in order according to final cutting age. A prescription rate of 0 indicates the earliest final cutting age, whilst a prescription rate of 1 indicates the latest final cutting age. In this case, the prescription rate is selected that maximizes the NPV for the youngest possible final cutting age. For a quantitative simulation at the local scale, however, it is necessary to select one prescription for each sub-compartment. Therefore, the prescription rates for each sub-compartment were decided over the total target area.

Based on the above, one prescription for 
each sub-compartment could be selected by considering the adjacency relationships. The simulation was run for 200 years. A long simulation was undertaken because, over long periods, the sum of NPV is almost equivalent to the SEV (soil expectation value) (Davis et al. 2001).

Using the data obtained from simulations to act as input data to generate estimates under the following procedure, the combinations of silvicultural practices for all sub-compartments were optimized. The genetic algorithm employed (Holland 1975) has been used in various forest management optimizations (Bettinger et al. 2002, Pukkala 2002). Based on a previous study that used the genetic algorithm (Yousefpour and Hanewinkel 2014), 50 random initial solutions were selected in order to set the values for the following optimization. The probabilities of cross-over and mutation, which could be from 0.01 to 1 , were set to the mean value (0.5). Based on previous studies (Falcão \& Borges 2001), these probabilities were kept constant throughout the prediction periods in this study.

When checking the validity of solutions derived from this optimization, the condition for stopping the optimization was as follows. We estimated the slope of the direct function (e.g. $y=a x+b)$ as the sum of the solutions of all the successful optimizations divided by the number of these, i.e. the average solution (Fig. 3). Assuming that this slope can be expected to be less than 0.01 , we decided to stop the optimization when the slope fell below this threshold; we then selected the best solution from the optimizations with slopes above this value.

The following formulae show the optimization process.

First, the compartment level optimizations were generated as follows.

$\max P=\sum_{i=1}^{l} \sum_{j=1}^{J} p_{i, j} x_{i, j}(r c, r p)$

Subject to $x_{i, j}=1$ or 0 , where $P$ - profitability (yen) derived from forestry prescriptions in a compartment, $p_{i, j}$ - profitability (yen) derived from forestry prescription $j$ in stand $i, I$ - the maximum number of stands in the target compartment, $J$ - the maximum number of optional forestry prescriptions at the stand level and $x_{i, j}$, which is a function of the connector ratio ( $r c)$ and the prescription ratio $(r p)$ as mentioned above is 1 or 0 . If forestry prescription $j$ is selected in stand $i, x_{i, j}$ is 1 , otherwise $x_{i, j}$ is 0 .

After the compartment level optimization, optimization based on the following formula for total target area was carried out.

$\max Z=\sum_{k=1}^{K} \sum_{l=1}^{L} P_{k, l} y_{k, l}$

where $P_{k, l}$ - profitability (yen) derived from forestry prescription $k$ conducted in compartment $l, K$ - the maximum number of compartments included in the total target area, $L$ - the maximum number of possible forestry prescriptions for compartments, $Z$ - the profitability (yen) of the total target area and $y_{k, l}$ is 0 or 1 . If forestry prescription $k$ is selected in compartment $l, y_{k, l}$ is 1 , otherwise $y_{k, l}$ is 0 .

After the optimization based on the previous restrictions (Nakajima et al. 2016), the ratios of short and long rotation forestry prescriptions were estimated for selected solutions as follows.

$$
\begin{aligned}
& R_{s}=\frac{A I_{s}}{A_{s}} \\
& R_{l}=\frac{A I_{l}}{A_{l}}
\end{aligned}
$$

where $R_{s}$ and $R_{l}$ are the ratios of short and long rotation forestry prescriptions, respectively. $A_{1}$ and $A_{\mathrm{s}}$ represent the total areas of sub-compartments chosen for a long and short rotation forestry prescriptions, respectively.

$A I_{l}$ and $A I_{s}$ are, respectively, the area where the long rotation is being practiced and the area where the short rotation is being practiced.

Based on labor requirements outlined by 
local forestry workers, three possible plans were identified, as follows. In Plan1, Plan2 and Plan3, the average ratios of short to long rotations were approximately $0.4,0.55$ and 0.7 , respectively. After the optimization, if the short and long rotation prescriptions ratios combined accounted for less than half the area, the following constraints were applied. The rates of (1) short or (2) long rotation prescriptions in a compartment should be more than 0.5 . However, the average total ratios $(0.4$, 0.55 and 0.7 ) for conducting prescriptions in all compartments were maintained as follows. To adjust upwards to more than 0.5 , the average total ratios for undertaking prescriptions in all compartments were maintained by reducing the ratios in compartments in which the ratio is initially more than 0.5 . This concept evens out the distribution of prescriptions for environmental functions, as mentioned in the introduction. Plan1, Plan2 and Plan3 were modified accordingly and then referred to as Plan 1', Plan 2' and Plan 3', respectively.

\section{Results}

Figure 4 shows the spatiotemporal simulation derived from the optimization. This figure shows the harvested sub-compartments based on the allocation of adjacency relationships and forest roads. It appears that the harvested sub-compartments expanded from sub-compartments adjacent to forest roads to sub-compartments away from the original forest roads. Eventually, almost all of the sub-compartments were harvested in the compartment (Fig. 4d).

It was confirmed that the optimization enabled us to establish a forest management plan by allocating the harvest area and considering the adjacency relationships. Figure 5 shows the results for the total area derived from the compartment optimizations. The figures show the ratios ( $R s$ and $R l$ in equation (5) and (6)) of prescriptions undertaken for the short and long rotation periods. These ratios refer to the proportion of the sub compartments where there was forestry activity or harvesting. In this study, three plans, based on the total ratios, were calculated for short and long rotation periods. The ratios of prescriptions in some compartments were always low because the economic value of these compartments was relatively low.

We were able to examine, visually, the intensity of forestry activity associated with short and long rotations. Prescriptions were not evenly distributed, with high ratios in some
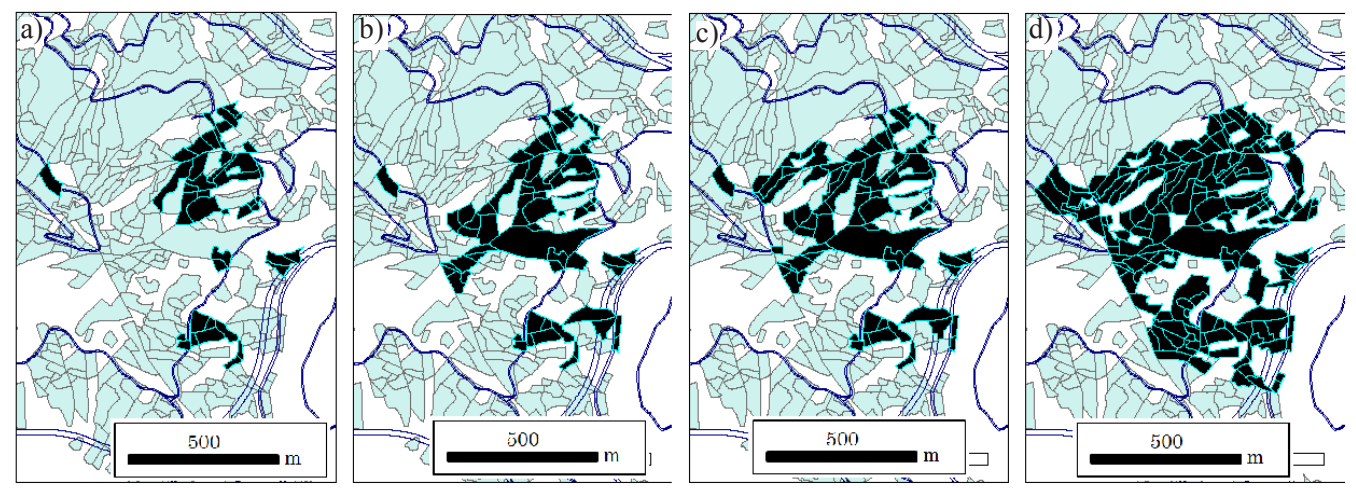

Figure 4 The spatiotemporal simulation derived from the optimization. The cobalt shading shows the area of the planted forest and the pale blue lines show the harvested forest. The navy-blue color line shows the initial forest road. a), b), c) and d) represent the situation after 20 years, 40 years, 60 years and 80 years, respectively. 
$\left.\mathrm{a}_{1}\right)$

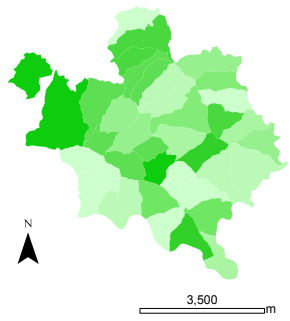

$\left.\mathrm{b}_{1}\right)$

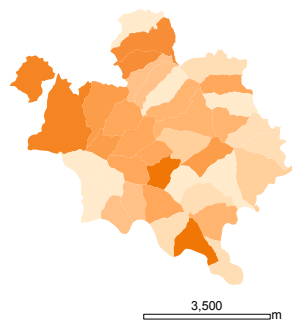

a2)

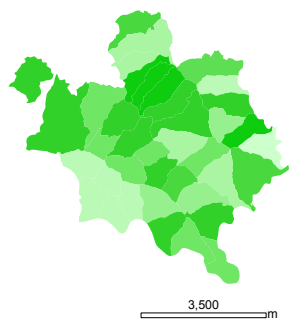

$\left.\mathrm{b}_{2}\right)$

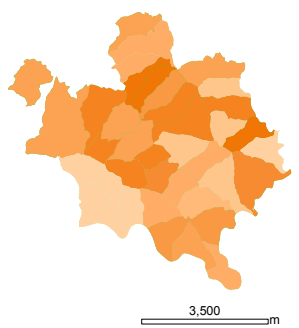

a)

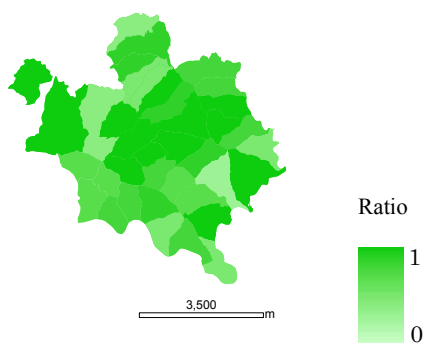

$\left.\mathrm{b}_{3}\right)$

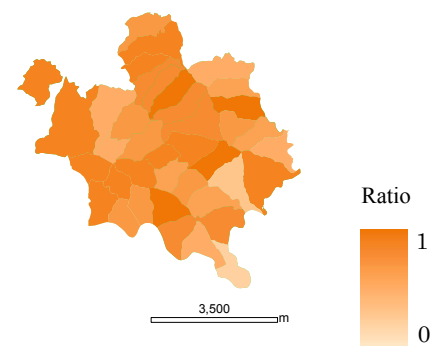

Figure 5 The spatial distribution of the proportion of sub-compartment area where forestry operations were undertaken, for short $\left(a_{1}-a_{3}\right)$ and long $\left(b_{1}-b_{3}\right)$ rotation periods. In this figure, $a_{1}-b_{1}, a_{2}-b_{2}$ and $a_{3}-b_{3}$ represent Plan1, Plan2 and Plan3, respectively.

compartments (more than 0.9 ) and very low ratios (less than 0.3 ) in others.

Figure 6 shows histograms of the ratios for conducting forestry operations under short and long rotation periods. The total average ratios of the compartment when conducting short and long rotation prescriptions under plans 1 (Fig. 6a1 and 6b1), 2 (Fig. 6a2 and 6b2) and 3 (Fig. 6a3 and 6b3) are 0.39, 0.57 and 0.72, respectively. The average ratio when conducting short rotations under plans 1 (Fig. 6a1), 2 (Fig. 6a2) and 3 (Fig. 6a3) are 0.41, 0.59 and 0.75 , respectively. The standard deviations of the ratios when conducting short rotations under plans 1 (Fig. 6a1), 2 (Fig. 6a2) and 3 (Fig. $6 \mathrm{a} 3$ ) are $0.38,0.29$ and 0.23 , respectively. The average ratio when conducting long rotations under plans 1 (Fig. 6a1), 2 (Fig. 6a2) and 3 (Fig. 6a3) are $0.37,0.56$ and 0.69 , respectively. The standard deviations of the ratios when conducting long rotations under plans 1 (Fig. 6b1), 2 (Fig. 6b2) and 3 (Fig. 6b3) are 0.28, 0.26 and 0.2 , respectively. These figures show that the ratios associated with undertaking the various prescriptions are not distributed evenly. In particular, there is a tendency for the ratios associated with short rotation periods to be either high (0.8-1) or low (0-0.3), rather than to have intermediate values.

In particular, there is a tendency for the distribution of ratios for short rotation periods (Fig. 6) to be uneven. The distribution presented in Fig. 6 is not bell-shaped, i.e. a normal distribution. Indeed, it appears to have two peaks. In figure a2, the proportion of each compartment that is harvested/actively managed peaks in the ranges $0.8-1$ and $0-0.3$. In figure a3, the proportion of each compartment that is harvested/actively managed peaks in the ranges $0.8-1$ and $0.3-0.5$.

Referring to the relationships between the ratios for conducting prescriptions under long 
$\left.a_{1}\right)$

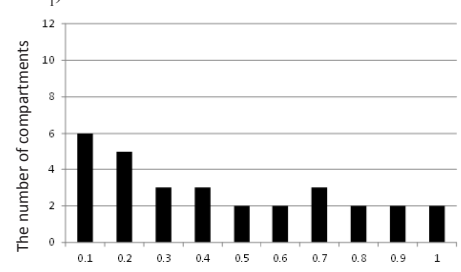

$\mathrm{b}_{1}$ )

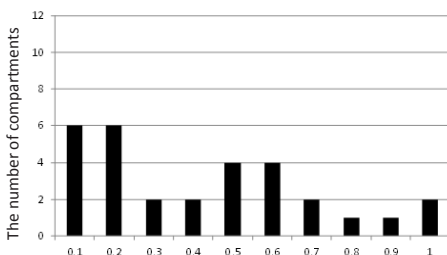

$\left.a_{2}\right)$

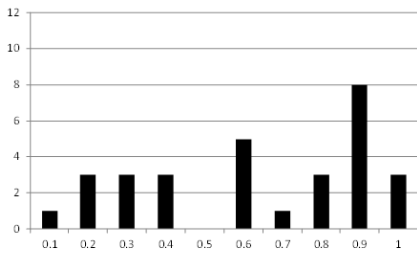

$\left.b_{2}\right)$

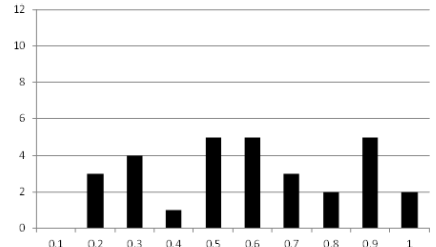

$\left.a_{3}\right)$

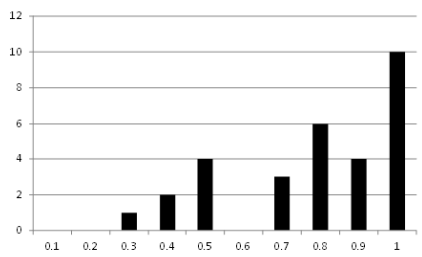

$\left.b_{3}\right)$

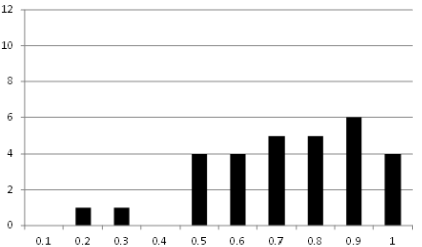

Figure 6 Histograms showing the of the number of compartments with each prescription activity ratio, for short $\left(\mathrm{a}_{1}-\mathrm{a}_{3}\right)$ and long $\left(\mathrm{b}_{1}-\mathrm{b}_{3}\right)$ rotation periods. In this figure, $\mathrm{a}_{1}-\mathrm{b}_{1}, \mathrm{a}_{2}-\mathrm{b}_{2}$ and $\mathrm{a}_{3}-\mathrm{b}_{3}$ represent Plan 1 , Plan 2 and Plan3, respectively. The plots $\mathrm{a}_{1,3}$ : the ratio when conducting short rotations (Rs in equation 5), while the plots $b_{1 \ldots 3}$ : the ratio when conducting long rotations ( $R l$ in equation 6$)$.
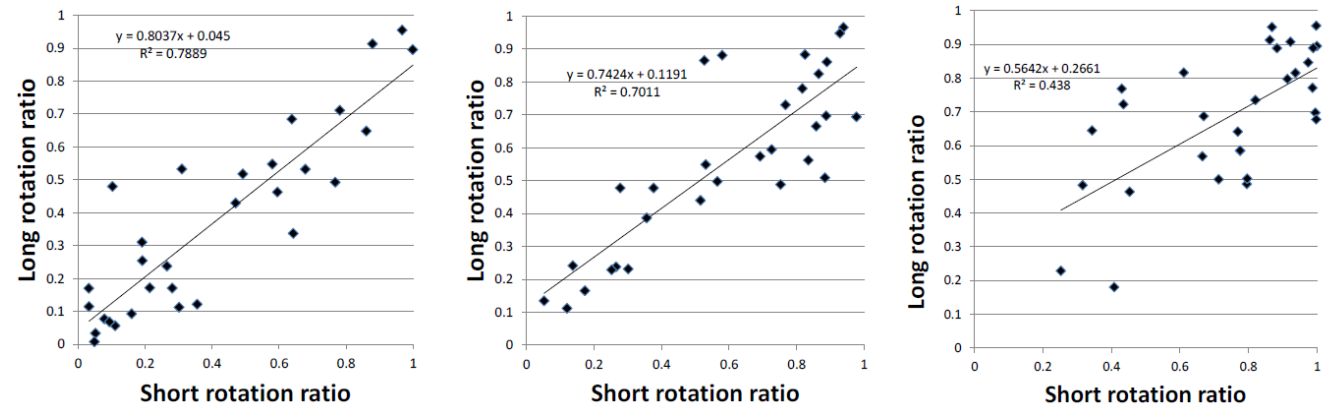

Figure 7 The relationships between the ratios when conducting prescriptions under long and short rotations under Plan 1(a), 2(b) and 3(c)

and short rotations, the coefficients of determination for fig. $7 \mathrm{a}, 7 \mathrm{~b}, 7 \mathrm{c}$ are $0.78,0.70$ and 0.43 , respectively, confirming the strong relationships between the two ratios. The slopes of the fitted lines in the figures are $0.80,0.74$ and 0.56 , respectively.

Figure 8 shows the distribution of the ratios when conducting prescriptions for short and long rotation periods. If we compare this figure with Fig. 5, we can see that the ratios are more evenly distributed.

The difference in distributions when the fo- cus is on economic forestry (Fig. 5) compared to distributing the forestry prescriptions more evenly (Fig. 8) can be seen by examining the two figures.

In this simulation (Figs 8 and 9), there are not strong relationships between the rates for short and long rotation prescriptions because these ratios are concentrated over a narrower range than those presented in Figs 5 and 6.

Fig 10 shows the differences in total profits between models for economic optimization and economic optimization with the prescrip- 
$\left.a_{1}\right)$

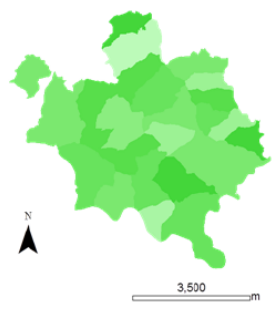

$\left.b_{1}\right)$

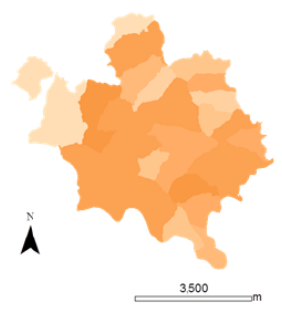

$\left.\mathrm{a}_{2}\right)$

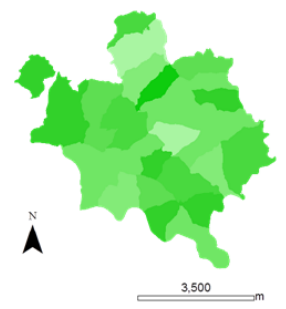

$\mathrm{b}_{2}$ )

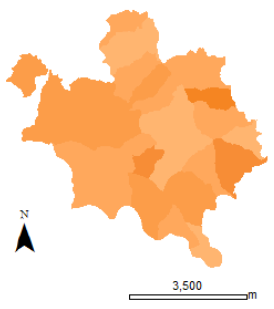

a3)

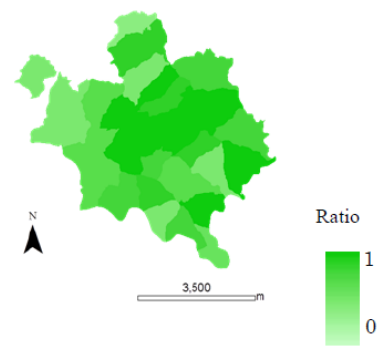

$\left.\mathrm{b}_{3}\right)$

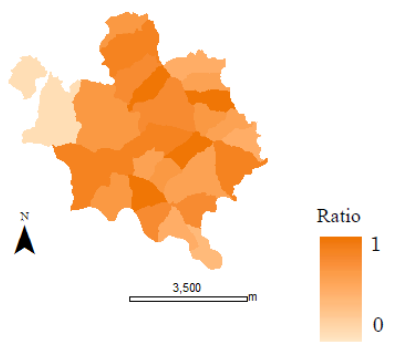

Figure 8 The spatial distribution of ratios when conducting prescriptions for the short $\left(a_{1}-a_{3}\right)$ and long $\left(b_{1}-b_{3}\right)$ rotation periods. In this figure, $a_{1}-b_{1}, a_{2}-b_{2}$ and $a_{3}-b_{3}$ represent Plan1', Plan2' and Plan3', respectively.

tion implementation evened-out.

The total profits in Plan 1, Plan 2 and Plan 3 (Fig. 5) are 179 hundred million yen, 331 hundred million yen and 443 hundred million yen, respectively. The total profits in Plan 1', Plan 2' and Plan 3' (Fig 8) are 143 hundred million yen, 268 hundred million yen and 417 hundred million yen, respectively. The differences between the two are 36 (Plan 1 minus Plan 1') hundred million yen, 62 (Plan 2 minus Plan 2') hundred million yen and 25 (Plan 3 minus Plan 3') hundred million yen, respectively. The ratios of differences between the two simulations are $20.3 \%$ (Plan 1 versus Plan 1'), 18.8 $\%$ (Plan 2 versus Plan 2') and $5.8 \%$ (Plan 3 versus Plan 3'), respectively. The average differences in profits per year are 1820 million yen, 3108 million yen and 1273 million yen, respectively. The profit difference between Plan3 and Plan 3' is relatively small because the prescription rates in the short and long rotations in almost all of the compartments are more than 0.5 .

The total average ratios under plans 1' (Fig. 9a1 and 9b1), 2' (Fig. 9a2 and 9b2) and 3' (Fig. $9 \mathrm{a} 3$ and $9 \mathrm{~b} 3$ ) are $0.46,0.60,0.72$, respectively. By comparing these average ratios for plans 1' (Fig. 9a1 and 9b1), 2' (Fig. 9a2 and 9b2) and 3' (Fig. 9a3 and 9b3) with those of plans 1 (Fig. 9a1), 2 (Fig. 9a2) and 3 (Fig. 9a3), it appears that these ratios are almost the same. The standard deviations of the short rotation ratio under plans 1' (Fig. 9a1), 2' (Fig. 9a2) and 3' (Fig. 9a3) are $0.17,0.17$ and 0.23 , respectively. The standard deviations of the long rotation ratio under plans 1' (Fig. 9b1), 2' (Fig. 9b2) and 3' (Fig. 9b3) are $0.17,0.10$ and 0.20 , respectively. The unevenness of the ratios when conducting prescriptions under the short and long rotations changed when the focus moved 

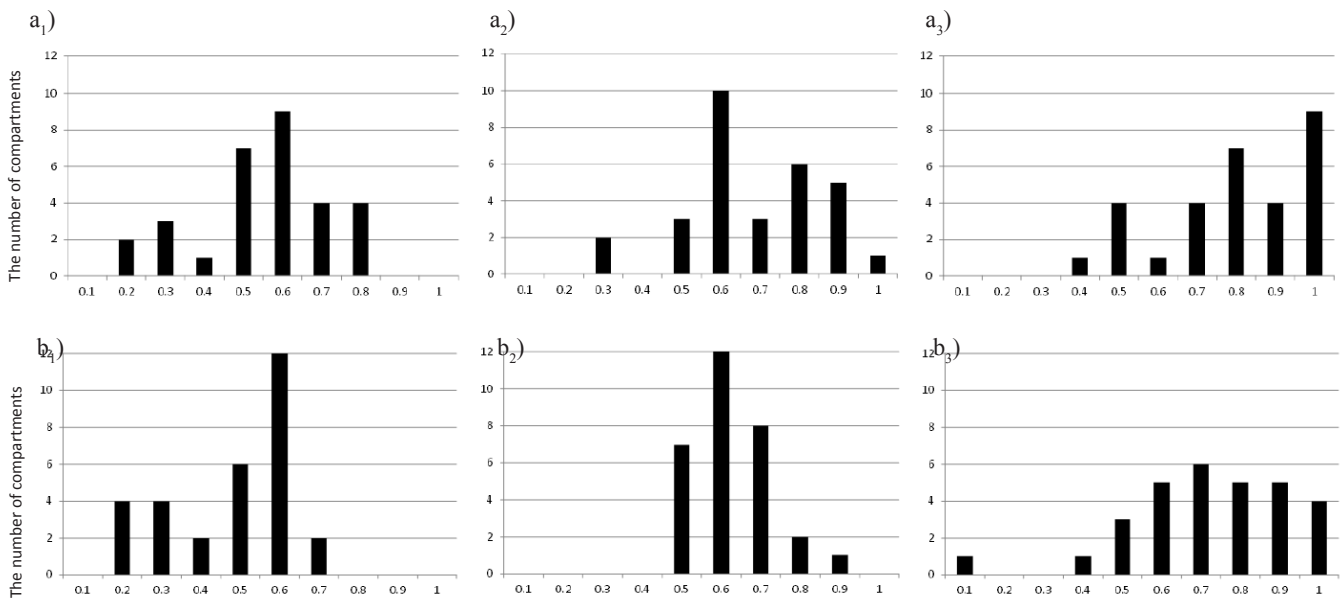

Figure 9 Histograms showing the of the number of compartments with each prescription activity ratio, for short $\left(a_{1}-a_{3}\right)$ and long $\left(b_{1}-b_{3}\right)$ rotation periods. In this figure, $a_{1}-b_{1}, a 2-b 2$ and $a_{3}-b_{3}$ represent Plan1, Plan2 and Plan3, respectively. The plots $\mathrm{a}_{1 . .3}$ : the ratio when conducting short rotations ( $R s$ in equation 5), while the plots $\mathrm{b}_{1 \ldots 3}$ : the ratio when conducting long rotations ( $R l$ in equation 6).

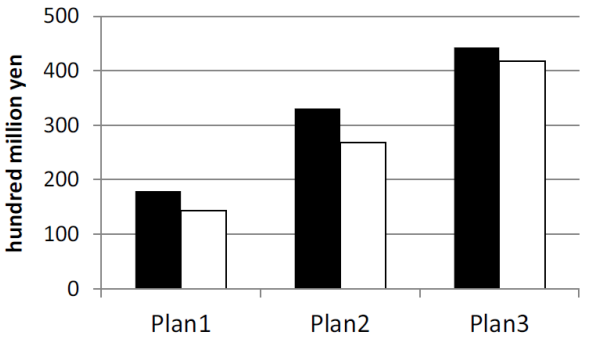

Figure 10 The differences in total profit comparing economic optimization and economic optimization with evening-out prescriptions. The black bars represent the rational economic plan (Fig. 5). The white bars show the total profit with a wider spread of prescriptions (Fig. 8).

from economic management planning to environmental management planning based on additional constraints for the prescription distribution.

\section{Discussion}

Imposing a different planning policy, for example a rational economic plan (Fig. 5), namely the concentrated scenario in this study, com- pared to an environmental plan that gives a more even geographical spread to the prescriptions (Fig. 8), namely the distributed scenario in this study, produced different results. However, the differences under Plan 3 were relatively small between the short rotation (Fig. $5 \mathrm{a} 3$ and Fig. 8a3) and long rotation (Fig. $5 \mathrm{~b} 3$ and Fig. 8b3). Because the ratios for the prescriptions associated with the short and long rotations under Plan 3 were already relatively high in many compartments (Fig. 5a3 and 5b3), redistribution for increased evenness had little effect.

As shown in Fig 7, the prescription ratios between the long and short rotations were positively correlated.

One of the main reasons for this strong correlation is the constraint of the adjacency relationships. In order to expand the harvest area, it is necessary to operate short rotation prescriptions simultaneously with other sub-compartments, and these would also be included in the long rotation prescriptions. Thus, it would be difficult to select between exclusively short or long rotation prescriptions in real forest management at the local scale. In practice, management should be considered by combining 
short and long rotations across a larger area. Generally, the higher the total average ratio for prescription implementation, the lower the coefficient of determination in Figure 7. In particular, the coefficient of determination for the relationship between short and long rotation prescriptions is relatively low in Fig. 6c. This is, at least in part, because with the higher total average ratio of prescription implementation (e.g. Fig. 6c), the range of ratios for both rotation periods is relatively narrow. Similarly, the absence of a relationship between the ratios for short and long rotation prescriptions in Fig. 7 is because of the small variation in ratios.

The proportion of each compartment that was harvested/actively managed under short rotation had a higher occurrence of high ratios ( 0.8 to 1.0$)$ than the proportion of each compartment that was harvested/actively managed under the long rotation (Fig. 5). Eventually, this would mean that short rotation prescriptions would have a stronger positive effect on forestry economics than long rotation prescriptions. According to previous studies (e.g. Vankooten et al. 2000), short rotation periods are usually selected as optimum for stands in which site indices and profitability are relatively high. It would be reasonable, therefore, for short rotations to be associated with higher ratios than long rotations. In addition, in compartments where the short rotation had a ratio of prescription implementation less than 0.3 and the ratio for the long rotation period was more than 0.5 , there would not be a large difference in profits derived from short and long rotation prescriptions, because the ratios of both are relatively low (Figs 6, 9 and 10).

Spatially, the prescription implementation ratios under the short and long rotations were more evenly distributed as figure 7 shows. Thus, the unevenness of the ratios under the long rotation period was obviously different between the rational economic management approach and management for environmental benefits.

We also demonstrated that the implementation ratios under the short and long rota156 tion periods were not distributed evenly. This suggests that the abandoned forest, where active management was not possible, would be likely to remain even in a scenario driven by economics. This fact is consistent with previous studies, which have suggested that the intensity of management activity, including thinning and harvesting, is concentrated in limited sub-compartments that have relatively better stand conditions (Hiroshima \& Nakajima 2006). This means that the forest manager should distinguish between favorable and unfavorable compartments when applying intensive prescriptions under the rational economic model. Concentrating intensive prescriptions in a limited area reduces forestry expenditure such as transportation costs of forestry machines.

There are also sound environmental reasons (particularly to do with increasing biodiversity) for leaving areas undisturbed in natural forests. This way deadwood stocks are increased - a key resource for many Red Book insect species in natural forests. On the other hand, some previous studies have shown that it is important to build environmental sustainability, such as biodiversity, landscape and carbon sequestration, by spreading forestry operations under different rotation periods evenly across a local area in order to maintain a patch-mosaic stand structure (Boyce 1995, Chabrerie et al 2007, Greco 2013).

Accordingly, it would be not feasible to focus forestry activity in just a few compartments. Because various forest operations can introduce a patch-mosaic stand structure, it would be better for environmental forest management to consider both short and long rotations. However, the difference in profitability under Plan 3 was relatively small (Fig. 6 and Fig. 8).

In contrast, profitability differed widely between the concentrated scenario (Fig. 4) and the distributed scenario (Fig. 7), especially under plans 1 and 2. These differences represent opportunity costs associated with distributing prescription implementation more evenly un- 
der short and long rotations in order to deliver environmental benefits.

Our results indicate that the reduction of economic value as shown in Fig. 9 is the result of managing for environmental benefits by redistributing forestry operations. So, it could be considered that the difference in profitability is an environmental opportunity cost, for which the government should provide compensation and consider constraints specifically with respect to allocating areas.

This study demonstrates the possibility of estimating such opportunity costs through modeling. If policymakers wish to limit economic forestry activities, economic support must be put in place. For example, subsidies should be introduced to cover opportunity costs arising from management for environmental benefit.

In Japan, forestry subsidies and the carbon credit system were discussed with respect to increasing the carbon stock under the Kyoto Protocol by expanding areas employing specific forest management prescriptions. However, the national political frameworks need to be changed and their permanency is not guaranteed. For sustainable forest management, it is important to plan over long periods of time and this could be helped by having long-term estimates of opportunity costs.

Naidoo \& Adamowicz (2006) calculated opportunity costs associated with landscape ecology. In this case, landscape diversity needs to be increased by ensuring variations in stand conditions at the local scale; this has to be achieved by distributing activities more evenly over short and long rotations. It is also important to maintain biodiversity (Lancia et al. 1989, Barlow et al. 2007, Nortongriffiths et al. $1995)$ in local forests by developing mosaics. For example, a mosaic of young and old forest maintained through short and long rotations is useful for increasing diversity at the local level (Boyce 1995). Previous studies have shown that forest mosaics help us to increase the diversity of mammals, insects and birds (Taboada et al. 2006, Redon et al. 2014). Our data are useful for estimating the opportunity costs as- sociated with such increases in environmental functions over long periods.

Our simulations are relevant to decision-making with respect to multiple forest functions - landscape, biodiversity etc - developing information presented in previous studies showing the cost of ensuring forest landscape diversity. The next challenge is to add natural forest areas to the analysis and evaluate multiple forest functions affected by human activities including short and long rotations.

\section{Conclusions}

We developed a simulation that accounted for and visualized the relationships between neighboring sub-compartments in a local forest area. Local forest management plans were defined, then visualized using a GIS. This system was applied to the following scenarios. First, a rational economic strategy focusing on conducting silvicultural operations in a limited number of economically favorable compartments. Second, an environmental strategy, focused on spreading forestry activities across all compartments. Silvicultural practice intensity was confirmed by digital mapping.

Based on the mapping and estimates of forestry profitability, we note the following points. First, opportunity costs represent a trade-off between the two silvicultural strategies. The opportunity costs have amounted to approximately $20 \%$ at this study site. Second, this result was discussed in relation to previous studies showing the relationships between public function and economic function in contexts where it is possible to simulate the trade-off between rational economic forestry plans and an environmental plan with a broader geographical spread to the prescriptions. We also demonstrated that it is possible to develop a simulation system for mapping strategies based on the allocation of existing forest roads and specific constraints. Finally, we confirmed that this model could be used as a decision-making tool for estimating the trade- 
off between the environmental and economic considerations in forest management.

\section{Acknowledgments}

The authors would like to thank the staff of the Forestry Administration of Miyazaki Prefectural Government for their assistance in collecting the data. This study was partly funded by Research Fellowships from the Japanese Science Promotion Society.

\section{References}

Anitha V., Muraleedharan P.K., Santheep K.V. 2008. Traditional bamboo products and their market sustainability in the wake of globalization - An opportunity cost analysis. Indian Forester 134: 428-434.

Barlow R., Grado S., Miller D., Grebner D. 2007. Opportunity costs of managing for wildlife habitat in the North Central Hills region of Mississippi. Southern Journal of Applied Forestry 31: 39-46.

Bettinger P., Greatz D., Boston K., Sessions J., Chung W. 2002. Eight heuristic planning techniques applied to three increasingly difficult wildlife planning problems. Silva Fennica 36:561-584.

Boyce S.G. 1995. Landscape forestry. John Wiley and Sons, Inc., New York, NY.

Chabrerie O., Roulier F., Hoeblich H., Sebert-Cuvillier E., Closset-Kopp D., Leblanc I., Jaminon J., Decocq G. 2007. Defining patch mosaic functional types to predict invasion patterns in a forest landscape. Ecological Applications 17: 464-481. DOI: 10.1890/06-0614

Clutter J.L., Fortson J.C., Pienaar L.V., Brister G.H., Bailey R.L. 1983. Timber management: a quantitative approach. John Wiley \& Sons, New York, 333 p.

Davis L.S., Johanson K.N. 1987. Forest management. McGraw-hill, New York, USA.

Davis L.S., Johanson K.N., Bettinger P., Howard T.E. 2001. Forest management to sustain ecological, economic and social values. McGraw-hill, New York, USA.

Falcão A.O., Borges J.G. 2001. Designing an evolution program for solving integer forest management scheduling models: An application in Portugal. Forest. Science 47:158-168.

Forestry Agency 2007. Annual report on trends of forest and forestry - fiscal year 2006. Tokyo: Japan Forestry Association, $17 \mathrm{p}$.

Fox B., Keller M.A., Schlosberg A.J., Vlahovich J.E. 1989. Opportunity costs of implementing forest plans. Environmental Management 13: 75-84. DOI: 10.1007/
BF01867588

Galik C.S., Jackson R.B. 2009. Risks to forest carbon offset projects in a changing climate. Forest Ecology and Management 257: 2209-2216. DOI: 10.1016/j.foreco.2009.03.017

Greco, S.E. 2013. Patch change and the shifting mosaic of an endangered bird's habitat on a large meandering river. River Research and Applications 29: 707-717. DOI: 10.1002/rra. 2568

Gulbrandsen L.H. 2005. Mark of sustainability? Challenges for fishery and forestry ecolabeling. Environment 47: 8-23. DOI: 10.3200/ENVT.47.5.8-23

Hiroshima T., Nakajima T. 2006. Estimation of sequestered carbon in Article-3.4 private planted forests in the first commitment period in Japan. Journal of Forest Research 11: 427-437. DOI: 10.1007/s10310-006-0236-5

Holland, J.H., 1975. Adaptation in natural and artificial systems. University of Michigan Press, Ann Harbor, MI.

IPCC .2000. Land use, land-use change and forestry. Special report of the Intergovernmental Panel on Climate Change. Cambridge: Cambridge University Press, 377 $\mathrm{p}$.

IPCC 2007. Climate Change 2007. Mitigation. Contribution of Working Group III to the Fourth Assessment Report of the Intergovernmental Panel on Climate Change. In: Metz, B., Davidson, O.R., Bosch, P.R., Dave, R., Meyer, L.A. (Eds.), Cambridge, Cambridge University Press, $852 \mathrm{p}$.

Kittredge D.B. 2005. The cooperation of private forest owners on scales larger than one individual property: International examples and potential application in the United States. Forest Policy and Economics 7:671-688. DOI: 10.1016/j.forpol.2003.12.004

Lancia R.A., Roise J.P., Adams D.A., Lennarts M.R. 1989. Opportunity costs of red-cockaded woodpecker foraging habitat. Southern Journal of Applied Forestry 13: $81-85$.

Lowell E.C., Becker D.R., Larson D., Rummer R., Wadleigh L. 2008. An integrated approach to evaluating the economic costs of wildfire hazard reduction through wood utilization opportunities in the southwestern United States. Forest Science 54: 273-283.

Mason C.L., Lippke B.R., Zobrist M.C., Sandoval G., Davis E.J. 2014. Comparing conditions of labor-intensive forestry and fire suppression workers. Society \& Natural Resources 27: 540-556. DOI: 10.1080/08941920.2014.888792

Miyazaki Prefecture Government 2015. Miyazaki forestry statistical data. Miyazaki Prefecture: Miyazaki, 179 p.

Naidoo R., Adamowicz W.L. 2006. Modeling opportunity costs of conservation in transitional landscapes. Conservation Biology 20: 490-500. DOI: 10.1111/j.15231739.2006.00304.x

Nakajima T., Kanomata H., Matsumoto M., Tatsuhara S., Shiraishi N. 2009a. The application of "Wood Max" for total optimization of forestry profits based on joint implementation silvicultural practices. Kyushu Journal of 
Forest Research 62: 176-180.

Nakajima T., Kanomata H., Ito T., Tatsuhara S., Shiraishi N. 2009b. Forest owner attitudes about tree thinning practices - a case study in Hayakawa, Yamanashi Prefecture, Japan. FORMATH 8: 179-194.

Nakajima T., Kanomata H., Matsumoto M., Tatsuhara S., Shiraishi N. 2011a. Cost-effectiveness analysis of subsidy schemes for industrial timber development and carbon sequestration in Japanese forest plantations. Journal of Forestry Research 22: 1-12. DOI: 10.1007/ s11676-011-0117-4

Nakajima T., Kanomata H., Matsumoto M., 2016. Visualization of optimized solution space using a simulation system for the development of local forest management planning. Ann. For. Res. 59(1): 117-128. DOI:10.15287/ afr.2016.556.

Nortongriffiths M., Southey C. 1995. The opportunity costs of biodiversity conservation in Kenya. Ecological Economics 12: 125-139. DOI: 10.1016/09218009(94)00041-S

Oka M. 2006. The study of analysis and valuation of harvesting operation by mechanization. Ph.D thesis of the University of Tokyo. (In Japanese)

Pukkala T. 2002. Multi-objective forest planning. Boston: Kluwer Academic, 207 p. DOI: 0.1007/978-94-0159906-1

Layton David F., Siikamaki J. 2009. Payments for ecosystem services programs: predicting landowner enrollment and opportunity cost using a beta-binomial model. Environmental \& Resource Economics 44: 415-439.
DOI: $10.1007 / \mathrm{s} 10640-009-9293-5$

Redon M., Luque S., Gosselin F., Cordonnier T. 2014. Is generalisation of unevenaged management in mountain forests the key to improve biodiversity conservation within forest landscape mosaics? Annals of Forest Science 71: 751-760. DOI: 10.1007/s13595-014-0371-7

Taboada A., Kotze D.J., Tarrega R., Salgado J.M. 2006. Traditional forest management: do carabid beetles respond to human-created vegetation structures in an oak mosaic landscape? Forest Ecology and Management 237: 436-449.

van Kooten G.C., Stennes B., Krcmar-Nozic E., van Gorkom R. 2000. Economics of afforestation for carbon sequestration in Western Canada. The Forestry Chronicle 76: 165-172. DOI: $10.5558 / \mathrm{tfc} 76165-1$

UNFCCC 2002. Report of the Conference of the Parties on its seventh session, held at Marrakesh from 29 October to 10 November 2001. Addendum. Part two: Action taken by the Conference of the Parties. Volume I. United Nations Office at Geneva: Geneva, 69 p.

UNFCCC 2012. Report of the Conference of the Parties serving as the meeting of the Parties to the Kyoto Protocol on its seventh session, held in Durban from 28 November to 11 December 2011. United Nations Office at Geneva, Geneva (Switzerland).

Yousefpour, R., Hanewinkel,M. 2014. Balancing decisions for adaptive and multipurpose conversion of Norway Spruce (Picea abies L. Karst) monocultures in the Black Forest area of Germany. Forest Science 60: 7384. DOI: $10.5849 /$ forsci.11-125 